in the spleen or liver or both after an interval of 24-48 hours, together with a fall in marrow radioactivity, can only be due to trapping and subsequent destruction of the patient's own red cells. Although the results thus obtained are only qualitative, this aspect of the investigation of haemolytic anaemia warrants further study.

We thank Professor Sir John Dacie FRS for his help and constructive criticism and Drs A Dawson, P D Robertson, and E C B Keat for allowing us to study and report details of these patients.

\section{References}

'Evans, R S, and Weiser, R S, Archizes of Internal Medicine, 1957, 100, 371. Worlledge, S M, and Blajchman, M A, British fournal of Haematology, 1972, 23, (suppl), 61.

"Pirofsky, B, Autoimmunization and the Autoimmune Haemolytic Anemias. Baltimore, Williams and Wilkins, 1969.

' Gilliland, B C, Baxter, E, and Evans, R S, New England fournal of Medicine, 1971, 285, 252.
${ }^{5}$ Crosby, W H, and Rappaport, H, Blood, 1956, 11, 929.

'Dacie, J V, and Lewis, S M, Practical Haematology, 5th edn. London, Churchill, 1975.

Gilliland, B C, Turner, E R, and Evans, R S, Fournal of Clinical Investigation, 1970, 40, 898.

* Dacie, J V, The Haemolytic Anaemias: Congenital and Acquired, 2nd edn. London, Churchill, 1962.

"Evans, R S, and Duane, R T, Blood, 1949, 4, 1196.

${ }^{10}$ Fisher, J A, Quarterly fournal of Medicine, 1947, 16, 245.

${ }^{11}$ Evans, R S, et al, Archives of Internal Medicine, 1951, 87, 48.

12. Brown, D L, Series Haematologica, 1974, 7, 348.

${ }^{13}$ Engelfriet, C P, et al, Series Haematologica, 1974, 7, 328.

14 Dacie, J V, Archives of Internal Medicine, 1975, 135, 1293.

15 Rosse, W F, Fournal of Clinical Investigation, 1971, 50, 534.

${ }^{16}$ Pisciotta, A V, and Hinz, J E, Proceedings of the Society of Experimental and Biological Medicine, 1956, 91, 356.

17 Yunis, J J, and Yunis, E, Blood, 1963, 22, 53.

${ }^{1 *}$ Hughes-Jones, N C, and Szur, L, British fournal of Haematology, 1957, 3, 320.

1: Williams, E D, et al, fournal of Laboratory and Clinical Medicine, 1974, 84, 134.

(Accepted 3 October 1977)

\title{
Doxorubicin cardiotoxicity: possible role of digoxin in its prevention
}

\author{
D GUTHRIE, A L GIBSON
}

British Medical fournal, 1977, 2, 1447-1449

out to determine whether it was possible to continue safely beyond $550 \mathrm{mg} / \mathrm{m}^{2}$ with the use of cardiac glycosides.

\section{Summary}

Twenty-nine patients with gynaecological cancers who received over $400 \mathrm{mg}$ of doxorubicin were monitored electrocardiographically to determine whether cardiac glycosides countered the adverse effects of high total doses of doxorubicin. Minor electrocardiographical changes were noted in five out of six patients who were not receiving a cardiac glycoside and four out of six who were receiving ouabain, and none of the 16 who were receiving digoxin. One other patient on digoxin stopped taking it and developed cardiomyopathy. One patient on ouabain also developed cardiomyopathy. So far nine patients on digoxin have received between 550 and 1000 $\mathrm{mg} / \mathrm{m}^{2}$ of doxorubicin without ill effect.

Cardiac glycosides are thought to prevent doxorubicin cardiomyopathy by competitively inhibiting doxorubicin at its receptor sites, but ouabain has a much shorter half life than doxorubicin and its metabolites and so is less effective than digoxin.

\section{Introduction}

Doxorubicin (adriamycin) is a cytotoxic antibiotic widely used in the treatment of malignancy. Its use has been limited, however, by the high incidence of fatal cardiomyopathy that occurs with large cumulative doses. ${ }^{1}$ The manufacturers recommend that the maximum cumulative dose should not exceed $550 \mathrm{mg} / \mathrm{m}^{2}$. After work reported on in 1974 by Lenaz² we set

Queen Elizabeth Hospital, Gateshead

D GUTHRIE, MB, MRCOG, research fellow, department of gynaecological oncology

A L GIBSON, MA, MRCP, consultant physician

\section{Patients and methods}

One of us (DG) has treated many patients with cytotoxic regimens that have included doxorubicin. Among these were 29 who had a total dose of doxorubicin of over $400 \mathrm{mg}$. These patients all had advanced gynaecological cancer and fell into three groups on the basis of their cardiac glycoside therapy: six patients had no cardiac glycoside; six were given ouabain $0.25 \mathrm{mg}$ intravenously 15 minutes before each dose of doxorubicin; and 17 were given digoxin $0.25 \mathrm{mg}$ day starting seven days before the first dose of doxorubicin and continuing until four weeks after the cessation of all cytotoxic treatment. The dose of digoxin was reduced only when electrocardiograms (ECGs) showed evidence of digoxin toxicity.

All patients had an ECG recorded before treatment and every three or four weeks after a total dose of $400 \mathrm{mg}$ doxorubicin had been reached. All ECGs were read blind by one of us (ALG) who knew only that a patient was receiving a cardiac glycoside but not which one. All three groups of patients were comparable as regards age (mean 54 years), blood pressure, and other factors concerning the cardiovascular system. There were no diabetic patients in the series, and no patient had any history of coronary artery disease.

\section{Results}

Minor ECG changes were noted in five of the six patients who were not taking cardiac glycosides and four of the six patients taking ouabain. The only changes noted in the digoxin group were those relating to the digoxin itself, except in one patient who stopped taking her digoxin and later developed cardiomyopathy. One other patient, who was taking ouabain, also developed cardiomyopathy. The case histories of these two patients are given below.

Statistical analysis comparing those receiving digoxin with those receiving other treatment, using a $\%^{2}$ test with Yates's correction for continuity, ${ }^{3}$ showed a highly significant difference $(P<0 \cdot 001)$. The patient who took herself off digoxin was omitted for the purposes of statistical analysis.

In the group not receiving cardiac glycosides doxorubicin treatment was stopped at $550 \mathrm{mg} / \mathrm{m}^{2}$. Two of the patients receiving ouabain had over $500 \mathrm{mg} / \mathrm{m}^{2}$ of doxorubicin: one had $600 \mathrm{mg} / \mathrm{m}^{2}$ and the other, who developed cardiomyopathy, had $1000 \mathrm{mg} / \mathrm{m}^{2}$. 
In the digoxin group nine patients had 550 to $1000 \mathrm{mg} / \mathrm{m}^{2}$ of doxorubicin and four of these were still having active treatment with doxorubicin at the time of writing. Except in the one patient who stopped digoxin there was no evidence of any cardiac abnormality in any of these patients.

\section{Case 1}

This patient was treated with doxorubicin and methotrexate for an advanced recurrent carcinoma of the cervix. She apparently took digoxin regularly until "some weeks" before day 384 of her treatment, when, having had a total of $1345 \mathrm{mg}$ of doxorubicin $\left(800 \mathrm{mg} / \mathrm{m}^{2}\right)$ her ECG showed conduction defects and low voltage, these changes being interpreted as early evidence of cardiomyopathy. Treatment with doxorubicin was stopped and her complete tumour remission maintained with methotrexate $65 \mathrm{mg}$ intravenously once every three weeks. The patient remained well until she presented with gross evidence of congestive heart failure on day 441 of her treatment. She was admitted to the medical ward and treatment was started with oxytetracycline $500 \mathrm{mg}$ four times a day, digoxin $0.25 \mathrm{mg} /$ day, frusemide $80 \mathrm{mg} /$ day, and spironolactone $100 \mathrm{mg} /$ day. Her condition improved and she was discharged home eight days later. Subsequently all medication was stopped apart from digoxin and methotrexate.

She remained well at the time of writing with no evidence of recurrent tumour or congestive heart failure. Her recent ECG seemed to have returned substantially towards normal. Illustrations of appropriate ECGs are shown in fig 1 . She was last seen 826 days after her first dose of doxorubicin.

\section{Case 2}

This patient was receiving treatment with doxorubicin and methotrexate for an advanced recurrent carcinoma of the cervix. She regularly had ouabain $0.25 \mathrm{mg}$ intravenously 15 minutes before every dose of doxorubicin. After receiving a total of $1015 \mathrm{mg}$ of doxorubicin $\left(650 \mathrm{mg} / \mathrm{m}^{2}\right)$ a progressive flattening of the $\mathrm{T}$ waves was noted in her routine ECGs. On the 579th day after the start of doxorubicin treatment she presented with congestive heart failure, and an ECG showed a low voltage tracing and flattened $\mathrm{T}$ waves. She had at that time received a total of $1540 \mathrm{mg}\left(1000 \mathrm{mg} / \mathrm{m}^{2}\right)$ of doxorubicin. Doxorubicin cardiomyopathy was diagnosed and she was admitted and treated with oxytetracycline $500 \mathrm{mg}$ four times a day, digoxin $0.25 \mathrm{mg} /$ day, frusemide $80 \mathrm{mg} /$ day, and spironolactone $100 \mathrm{mg} /$ day. Her condition improved and 15 days later she was discharged home. All cardiac treatment except for digoxin was subsequently withdrawn and an attempt was made to maintain the complete remission of her carcinoma of the cervix by using methotrexate $40 \mathrm{mg} / \mathrm{m}^{2}$ intravenously every three weeks. She remained well, and ECGs showed increased voltage and returned substantially to normal (fig 2). Evidence of

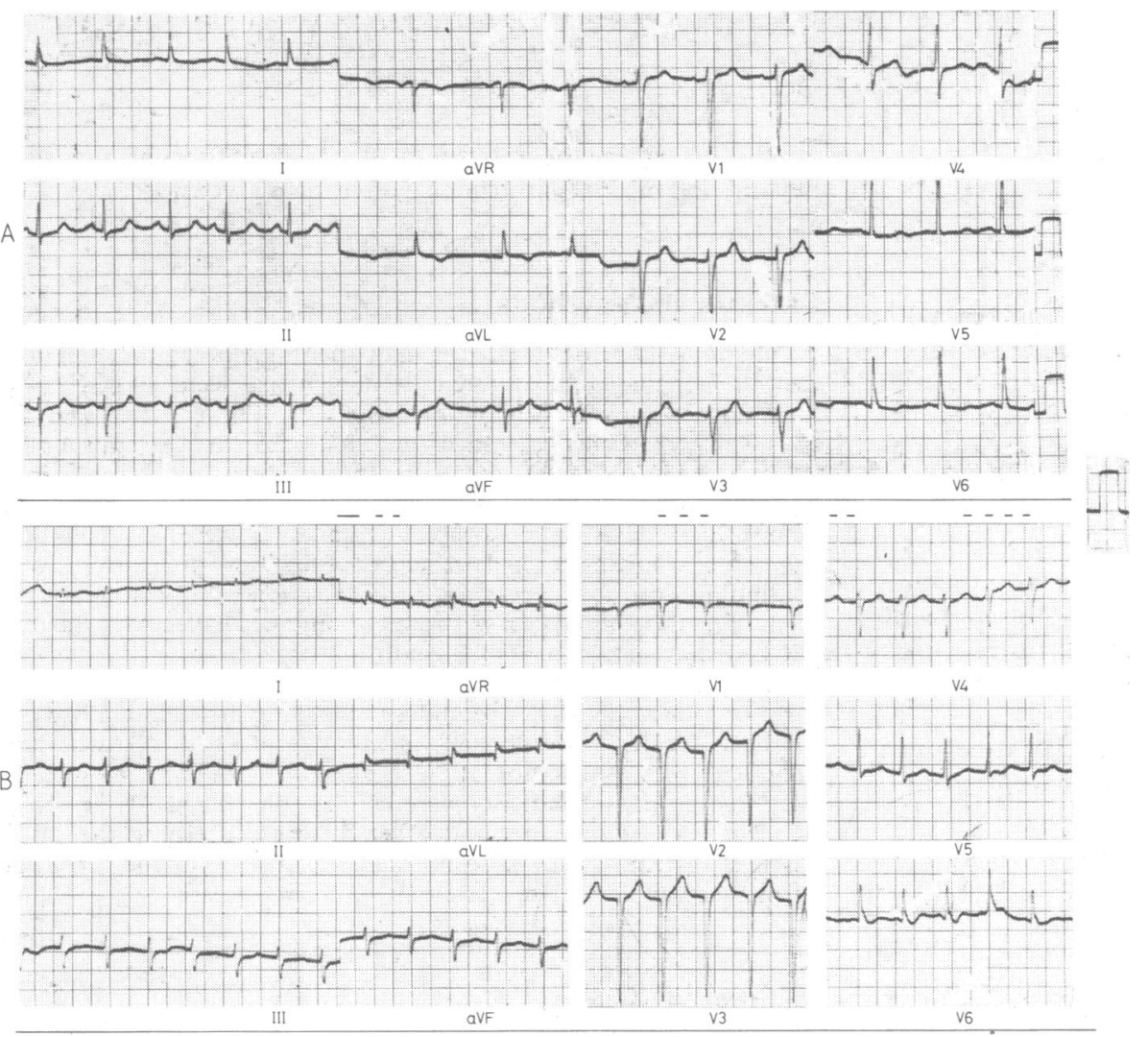

FIG 1-Case 1. (a) Baseline tracing, which was substantially normal except for $\mathrm{T}$-wave inversion in lead VL. (b) Tracing taken during episode of intoxication showing generalised voltage reduction, sinus tachycardia, and development of deep $\mathrm{Q}$ waves in right chest leads. (c) Tracing taken after recovery showing return to normal except for effects of digoxin. 
FIG 2-Case 2. (a) Baseline tracing showing normal pattern except for slightly shortened PR interval. (b) Tracing taken during intoxication showing generalised voltage reduction, sinus tachycardia, and deep $Q$ waves in right chest leads. (c) Tracing taken after recovery showing only effects of digoxin.
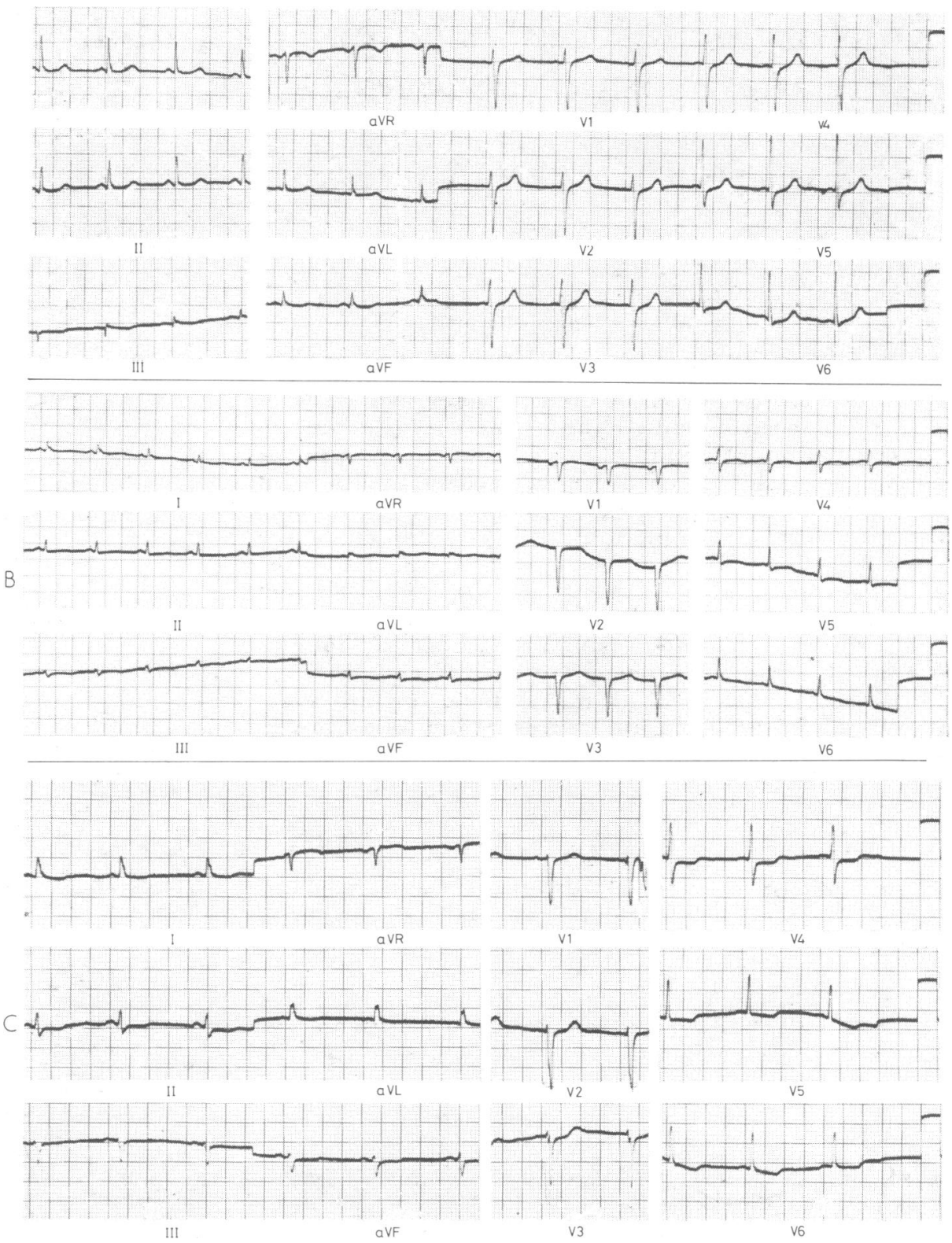

reactivation of her tumour was found at 712 days and she died from carcinoma of the cervix at 826 days.

\section{Discussion}

Cardiac glycosides are thought to prevent doxorubicin cardiomyopathy by acting as competitive inhibitors occupying the same receptor sites as doxorubicin and its metabolites. It therefore seemed illogical to continue using ouabain, as it has a much shorter half life than either doxorubicin or its metabolites. We therefore used digoxin, although patients who had started on ouabain were continued on it. For the same reason we thought that if digoxin itself was used for only a short period it was not likely to be effective, as has been shown by several animal experiments relating to the prevention of doxorubicin cardiomyopathy.

Damage to voluntary muscle may occur in patients receiving doxorubicin, ' and before we started using digoxin we recorded a $58^{\circ}{ }^{\circ}$ incidence of profound muscle weakness in patients who had had over $400 \mathrm{mg}$ of doxorubicin. After we started using digoxin the incidence fell to $8^{\circ}{ }_{0}$ and the patients who did suffer muscle weakness experienced it in a much less severe form. Absorbed digoxin reaches levels in voluntary muscle about $20^{\circ}{ }_{0}$ of those in the heart, ${ }^{4}$ and the presence of digoxin in voluntary muscle might account for the reduced incidence of muscle weakness.

Oxytetracycline has a similar molecular structure to doxorubicin and was therefore used to treat the cardiomyopathies in the hope that it might displace doxorubicin or its metabolites from cardiac muscle. Whether in fact it played any part in the recovery of the patients remains a matter for conjecture. Nevertheless, we must emphasise that reports from all over the world suggest that doxorubicin cardiomyopathy is often fatal and certainly not as easy to treat as these two case histories would suggest.

We gratefully acknowledge the financial assistance given by the North of England Cancer Research Campaign.

\section{References}

1 Lefrak, E A, et al, Cancer, 1973, 32, 302.

2 Lenaz, L, The Clinical Performance of Adriamycin in Leukaemias and Solid Tumours, ed A P Launchbury, p 5. Pharmitalia (UK), 1974.

3 Yates, F, fournal of the Royal Statistical Society, 1934, No 1, p 217.

4 Docherty, J E, in Basic and Clinical Pharmacology of Digitalis, ed B H Marks and A M Weissler, p 230. Springfield, Illinois, Thomas, 1972.

(Accepted 27 September 1977) 